\title{
Appoptosin is a Novel Pro-Apoptotic Protein and Mediates Cell Death in Neurodegeneration
}

\author{
Han Zhang, ${ }^{1,2 \star}$ Yun-wu Zhang, ${ }^{1,2 \star}$ Yaomin Chen, ${ }^{2 \star}$ Xiumei Huang, ${ }^{1,2}$ Fangfang Zhou, ${ }^{3}$ Weiwei Wang, ${ }^{1}$ Bo Xian, ${ }^{4}$ \\ Xian Zhang, ${ }^{1}$ Eliezer Masliah, ${ }^{5}$ Quan Chen, ${ }^{6}$ Jing-Dong J. Han, ${ }^{4}$ Guojun Bu, ${ }^{1}$ John C. Reed, ${ }^{2,7}$ Francesca-Fang Liao, ${ }^{2,8}$ \\ Ye-Guang Chen, ${ }^{3}$ and Huaxi $\mathrm{Xu}^{1,2}$ \\ ${ }^{1}$ Fujian Provincial Key Laboratory of Neurodegenerative Disease and Aging Research and Institute of Neuroscience, College of Medicine, Xiamen University, \\ Xiamen, Fujian 361005, China, ${ }^{2}$ Neurodegenerative Disease Research Program, Sanford-Burnham Medical Research Institute, La Jolla, California 92037 , ${ }^{3}$ State Key \\ Laboratory of Biomembrane and Membrane Biotechnology, School of Life Sciences, Tsinghua University, Beijing, China 100084, ${ }^{4} \mathrm{CAS}$ Key Laboratory of Molecular \\ Developmental Biology and Center for Molecular Systems Biology, Institute of Genetics and Developmental Biology, the Chinese Academy of Sciences, Beijing \\ 100101, China, ${ }^{5}$ Department of Pathology, University of California San Diego, La Jolla, California 92093, ${ }^{6}$ Institute of Zoology, Chinese Academy of Sciences, Beijing \\ 100101, China, ${ }^{7}$ Program on Apoptosis and Cell Death Research, Sanford-Burnham Medical Research Institute, La Jolla, California 92037, and ${ }^{8}$ Department of \\ Pharmacology, University of Tennessee Health Science Center, College of Medicine, Memphis, Tennessee 38163
}

Apoptosis is an essential cellular process in multiple diseases and a major pathway for neuronal death in neurodegeneration. The detailed signaling events/pathways leading to apoptosis, especially in neurons, require further elucidation. Here we identify a $\beta$-amyloid precursor protein (APP)-interacting protein, designated as appoptosin, whose levels are upregulated in brain samples from Alzheimer's disease and infarct patients, and in rodent stroke models, as well as in neurons treated with $\beta$-amyloid (A $\beta$ ) and glutamate. We further demonstrate that appoptosin induces reactive oxygen species release and intrinsic caspase-dependent apoptosis. The physiological function of appoptosin is to transport/exchange glycine/5-amino-levulinic acid across the mitochondrial membrane for heme synthesis. Downregulation of appoptosin prevents cell death and caspase activation caused by glutamate or A $\beta$ insults. APP modulates appoptosin-mediated apoptosis through interaction with appoptosin. Our study identifies appoptosin as a crucial player in apoptosis and a novel pro-apoptotic protein involved in neuronal cell death, providing a possible new therapeutic target for neurodegenerative disorders.

\section{Introduction}

Cellular apoptosis is mediated by either caspase-dependent or caspase-independent pathways (Hail et al., 2006). Caspasedependent pathways can be classified as intrinsic or extrinsic and are associated with caspase- 9 and caspase-8, respectively, both of which activate caspase- 3 at later stages (Hail et al., 2006). During

Received July 31, 2012; revised Aug. 31, 2012; accepted Sept. 5, 2012.

Author contributions: Y.-W.Z., Y.-G.C., and H.X. designed research; H.Z., Y.-W.Z., Y.C., X.H., F.Z., W.W., B.X., and X.Z. performed research; E.M., Q.C., and J.-D.J.H. contributed unpublished reagents/analytic tools; H.Z., Y.-W.Z., G.B., J.C.R., F.-F.L., Y.-G.C., and H.X. analyzed data; H.Z., Y.-W.Z., and H.X. wrote the paper.

This study was supported in part by National Institutes of Health Grants R01AG038710, R01AG021173, R01NS046673, R01AG030197, and R03AG034366 (H.X.); R01NS054880 and R01AG031893 (F.-F.L.); AG5131 and AG18440 (E.M.); R21AG038968 (Y.-W.Z.), and grants from the Alzheimer's Association (H.X., Y.-W.Z., and F.-F.L.), the American Health Assistance Foundation (H.X.), National Natural Science Foundation of China (30840036 and 30973150 to Y.-W.Z.; 30921004 and 30930050 to Y.G.C.), National Basic Research Program of China (2010CB833706 to Y.G.C.), the 973 Prophase Project (2010CB535004 to Y.-W.Z.), and Natural Science Foundation of Fujian Province of China (2009J06022 to Y.-W.Z., 2010J01233 to H.X., and 2010J01235 to X.Z.). Y.-W.Z. is supported by the Program for New Century Excellent Talents in Universities, the Fundamental Research Funds for the Central Universities, and Fok Ying Tung Education Foundation. We thank G. Xi, C. Yu, and R. Thompson for technical support, S.A. Lipton for helpful discussion, and Y. Shen for providing Alzheimer's disease patient and control brain samples.

The authors declare no competing financial interests.

*H.Z., Y.-W.Z., and Y.C. contributed equally to this work.

Correspondence should be addressed to Huaxi Xu, Neurodegenerative Disease Research Program, SanfordBurnham Medical Research Institute, 10901 North Torrey Pines Road, La Jolla, CA 92037, E-mail: xuh@sanfordburnham.org; or Ye-Guang Chen, State Key Laboratory of Biomembrane and Membrane Biotechnology, School of Life Sciences, Tsinghua University, Beijing 100084, China, E-mail: ygchen@tsinghua.edu.cn.

DOI:10.1523/JNEUROSCI.3668-12.2012

Copyright $\odot 2012$ the authors $\quad 0270-6474 / 12 / 3215565-12 \$ 15.00 / 0$ the intrinsic caspase-dependent pathway, cytochrome $c$ is released from mitochondria into the cytoplasm where holocytochrome $c$ (heme-bound cytochrome $c$ ) interacts with dATP, APAF-1, and caspase- 9 to form the apoptosome, triggering a cascade resulting in apoptosis, whereas apocytochrome $c$ (hemefree cytochrome $c$ ) still binds APAF-1 but prevents apoptosome formation, caspase- 9 activation, and apoptosis (Martin et al., 2004; Hail et al., 2006).

Dysfunctional apoptosis underlies the pathological basis for many diseases including Alzheimer's disease (AD), one of the most common neurodegenerative disorders. AD is characterized by excessive accumulation of senile plaques in the brain. Senile plaques are composed of $\beta$-amyloid ( $\mathrm{A} \beta$ ) peptides derived from $\beta$-amyloid precursor protein (APP) through sequential cleavages by $\beta$ - and $\gamma$-secretases (Zhang and $\mathrm{Xu}, 2007)$. $\mathrm{A} \beta$ is highly toxic to neurons and can trigger a cascade of pathogenic events leading to cell death (Hardy and Higgins, 1992). However, the mechanism underlying $A \beta$ 's neurotoxicity remains largely unclear. In addition to $\mathrm{A} \beta, \gamma$-secretase cleavage of APP generates APP intracellular domain (AICD), which was found to have neurotoxic effects (Passer et al., 2000; Giliberto et al., 2008; Zheng and Koo, 2011), enhance p53-mediated apoptosis (Ozaki et al., 2006), and regulate transcription of certain genes involved in cell survival/ tumorigenesis (Ryan and Pimplikar, 2005; Alves da Costa et al., 2006; Zhang et al., 2007). 
To further study the neurotoxicity of AICD and its associated proteins, we performed yeast-two-hybrid assays and identified a then hypothetical protein, SLC25A38, which interacts with APP/ AICD. Furthermore, we found that SLC25A38 is pro-apoptotic. Therefore, we assigned SLC25A38 the name appoptosin. Appoptosin belongs to the mitochondrial solute carrier family (SLC25), which is encoded by nuclear genes and synthesized in the cytosol. Newly synthesized proteins are then translocated into mitochondrial inner membranes and function to transport various substrates between the cytoplasm and mitochondria (Haitina et al., 2006). However, information on the function of appoptosin was completely unknown until recent studies found that mutations in the SLC25A38 gene are associated with congenital sideroblastic anemia and hypothesized that appoptosin/SLC25A38 functions as a transporter of glycine/5-amino-levulinic acid ( $\delta$-ALA) (Guernsey et al., 2009). Transport of glycine/ $\delta$-ALA across the mitochondria is crucial for the synthesis of heme. Cellular heme is mostly associated with proteins and protein-bound heme and free heme are maintained in a delicate homeostatic balance. However, excessive heme, especially free heme, may promote deleterious cellular processes such as overproduction of reactive oxygen species (ROS), impairment of lipid bilayers and organelles, destabilization of the cytoskeleton, and inflammation (Atamna, 2004; Kumar and Bandyopadhyay, 2005). Multiple lines of evidence suggest that heme metabolism is altered in $\mathrm{AD}$ and other neurodegenerative disorders (Ryter and Tyrrell, 2000; Atamna, 2004). Herein, we found that appoptosin regulates intrinsic caspase-dependent apoptosis through governing heme biosynthesis. Moreover, we demonstrated that appoptosin is involved in neuron death associated with neurodegeneration.

\section{Materials and Methods}

Cells, antibodies, and reagents. Mouse neuroblastoma N2a cells were maintained in an equal volume mixture of high-glucose DMEM and Opti-MEM with 5\% fetal bovine serum (FBS) and penicillin/streptomycin. Human neuroblastoma SY5Y cells and human HEK293T cells were maintained in high-glucose DMEM with 10\% FBS and penicillin/streptomycin. N2a and SY5Y cells used for heme assays were cultured in serum-free neurobasal medium to exclude any interference of heme from the serum. Primary cortical neuronal cells from embryonic day 17 (E17) rat pups and postnatal day 0 (P0) mouse pups were maintained in neurobasal medium supplemented with B27 and $0.8 \mathrm{~mm}$ glutamine.

Antibodies used were as follows: anti-appoptosin (SLC25A38) from Abcam and Sigma; anti-total cytochrome $c$, anti-cleaved caspase-3, anticleaved caspase-8, anti-cleaved caspase-9, anti-Bcl-2, anti-phosphoBcl-2, anti-Bcl-xl, anti-Bax, anti-Bad, and anti-phospho-Bad from Cell Signaling Technology; anti-apocytochrome $c$ from BD PharMingen; anti-HA, anti- $\beta$-actin, and anti- $\alpha$-tubulin from Sigma; anti-Myc (9E10) and anti-AIF from Santa Cruz Biotechnology; and anti-Endo-G from EMD Biosciences. Rabbit antibody against human appoptosin and mouse monoclonal antibody 22c11 against the APP $\mathrm{N}$ terminus were developed in our laboratory. Fluorescence-conjugated secondary antibodies were from Invitrogen.

Apoptosis inducer BH3I, noncaspase-dependent apoptosis inhibitor DPQ and pan-caspase inhibitor Z-VAD were from Calbiochem. Tumor necrosis factor- $\alpha$ (TNF- $\alpha$ ), cycloheximide, staurosporine, monosodium glutamate, $N$ acetyl-1-cysteine (NAC), carbamyl cyanidem-chlorophenyl-hydrazone (mCCCP),2,7-dichlorodihydrofluorescein diacetate (CM- $\left.\mathrm{H}_{2} \mathrm{DCFDA}\right)$, propidium iodide (PI), 4',6-diamidino-2-phenylindole (DAPI), and succinylacetone (SA) were from Sigma. Conditioned media containing naturally secreted $\mathrm{A} \beta$ oligomers were from cultures of 7PA2 Chinese hamster ovary cells (Walsh et al., 2002). A $\beta_{1-42}$ peptide was from Anaspec.

Yeast-two-hybrid. Matchmaker GAL4 Two-Hybrid System 3 kit (including pGBKT7 plasmid, AH109 yeast strain, YPD yeast culture medium, SD/DO medium, and a human fetal brain cDNA library) was
Table 1. Information of AD and infarct patients and respective controls used in this study

\begin{tabular}{|c|c|c|c|c|c|}
\hline \multicolumn{3}{|l|}{ Patients } & \multicolumn{3}{|l|}{ Controls } \\
\hline Case & Gender & Age & Case & Gender & Age \\
\hline \multicolumn{6}{|c|}{ AD patients and controls } \\
\hline $99-39$ & M & 72 & $98-33$ & $\mathrm{~F}$ & 82 \\
\hline 99-15 & M & 83 & $99-25$ & $\mathrm{~F}$ & 76 \\
\hline $01-05$ & M & 88 & $98-32$ & M & 83 \\
\hline $01-13$ & M & 87 & $98-34$ & $\mathrm{~F}$ & 73 \\
\hline $01-09$ & $\mathrm{~F}$ & 83 & $98-23$ & M & 68 \\
\hline $03-02$ & M & 76 & $00-49$ & $\mathrm{~F}$ & 86 \\
\hline $01-17$ & $\mathrm{~F}$ & 78 & $97-17$ & M & 78 \\
\hline $01-48$ & $\mathrm{~F}$ & 97 & & & \\
\hline $03-07$ & M & 67 & & & \\
\hline $01-34$ & $\mathrm{~F}$ & 89 & & & \\
\hline \multicolumn{6}{|c|}{ Infarct patients and controls } \\
\hline 5105 & $\mathrm{~F}$ & 74 & $99-25$ & $\mathrm{~F}$ & 76 \\
\hline 5341 & $\mathrm{~F}$ & 77 & $98-19$ & $\mathrm{~F}$ & 87 \\
\hline 5167 & M & 83 & $98-32$ & M & 83 \\
\hline 5455 & $\mathrm{~F}$ & 93 & 4996 & M & 91 \\
\hline
\end{tabular}

purchased from Clontech. AICD (the last 57 aa of APP C terminus) with a short linker (triple GGGGS) was inserted into a pGBKT7 vector between EcoRI and BamHI sites. A yeast-two-hybrid screening was performed following the manufacturer's protocols.

$\beta$-galactosidase activity ( $\beta$-gal) assay. Full-length SLC25A38 cDNA was cloned in the pGADT plasmid. pGBKT7 or pGBKT7-AICD plasmids were coexpressed with $\mathrm{pGADT}$ or pGADT-SLC25A38 plasmids in yeasts. Yeast was cultured on SD/-Leu/-Trp medium at $30^{\circ} \mathrm{C}$ overnight, and transferred to YPD medium. Yeast was collected when A600nm reached 1.0-1.5 and frozen in liquid nitrogen three times. Lysates were incubated with the ONPG substrate and incubated at $30^{\circ} \mathrm{C}$ until color appeared. $\mathrm{Na}_{2} \mathrm{CO}_{3}$ was applied to stop the reaction and readings at A420nm were taken to measure $\beta$-gal activity.

Coimmunoprecipitation. HEK293T cells transfected with appoptosin and SY5Y naive cells were lysed with CelLytic M Cell Lysis Reagent (Sigma) supplied with a protease inhibitor mixture (Roche). Cell lysates were subjected to immunoprecipitation with the indicated antibodies and rProtein A-Sepharose beads (Biochain Institute), followed by Western blot.

Bimolecular fluorescence complementation assay. The biomolecular fluorescence complementation (BiFC) assay followed a previously described protocol (Hu et al., 2002). Briefly, sequences encoding amino acids residues 1-154 of yellow fluorescent protein (YFP) (nYFP) and amino acids residues 155-238 of YFP (cYFP) were fused to APP/AICD and appoptosin at their C termini, respectively. HEK293T cells were cotransfected with APP/AICD-nYFP and appoptosin-cYFP for $24 \mathrm{~h}$, stained with Mito Tracker Red (Invitrogen), fixed, and subjected to fluorescent microscopy analyses.

Mitochondrial isolation. Mitochondria of cells were isolated with a Mitochondrial Isolation Kit for Mammalian Cells (Thermo Scientific), following the manufacturer's protocol. Equal amounts of protein lysates of mitochondrial and cytosol fractions were subjected to Western blot analysis.

Annexin V staining. Cells were stained with Annexin V-FITC Apoptosis Kit (Biovison), followed by flow cytometry analysis (FACS).

Immunohistochemistry. Mouse coronal brain sections or human cortical brain sections were permeabilized, immunostained with anti-appoptosin antibody (Sigma), incubated with biotinylated secondary antibody and avidin-biotin-peroxidase complex (ABC) Elite reagent (Vector Laboratories), developed with diaminobenzidine (DAB) substrate (Vector Laboratories), and visualized under a light microscope. For the peptide competition experiment, the anti-appoptosin antibody (Sigma) was pre-incubated with the antigen peptide "LYSLKQYFLRGHPPTA LESVMLGVGSRSVAGVCMSPITVIKTRYESGKYG.”

Immunofluorescence microscopy. For subcellular localization of appoptosin, human brain cortical sections were permeabilized, immunostained with antibodies against appoptosin and COX IV, incubated with 


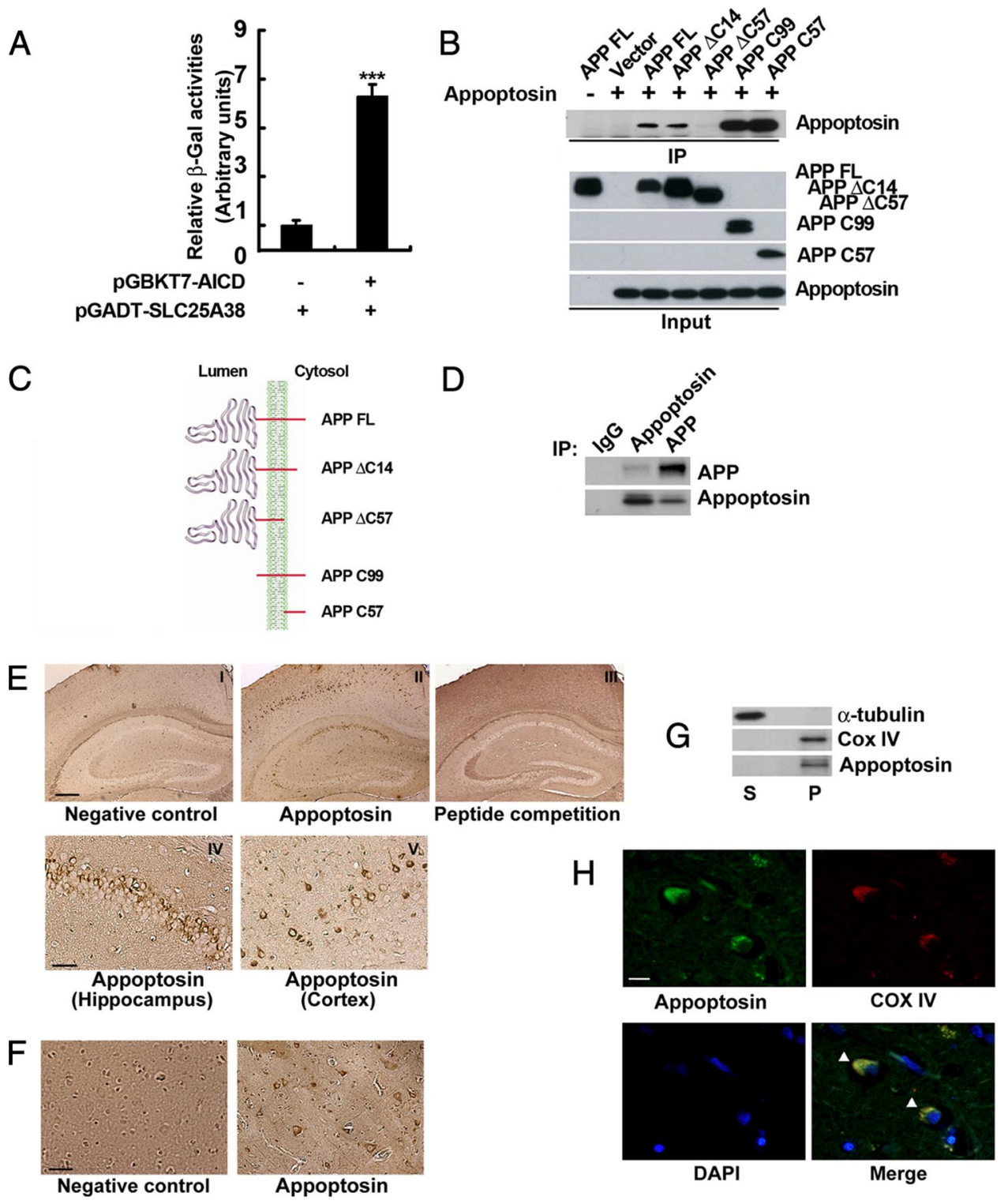

Figure 1. Appoptosin (SLC25A38) interacts with APP/AICD and localizes in neuronal mitochondria. $A$, The plasmids pGBKT-AICD and pGADT7-SLC25A38 were coexpressed in yeast. Cell lysates were assayed for $\beta$-gal activity. $N=3,{ }^{* * *} p<0.001$. B. Hemagglutinin (HA)-tagged appoptosin was coexpressed with control or APP variant vectors that were Myc-tagged. Cell lysates were immunoprecipitated (IP) with Myc antibody, followed by Western blot with HA antibody. Expression of appoptosin and APP variants were detected in input. C, Scheme of membrane structure of various APP forms used in this study, including full-length (FL) APP, APP lacking the last 14 aa ( $\triangle C 14)$, APP lacking the entire AICD domain $(\Delta C 57)$, APP-CTF (C99), and AICD (C57). D, SY5Y cell lysates were immunoprecipitated with rabbit lgG, appoptosin antibody, or APP antibody, followed by Western blot with APP and appoptosin antibody, respectively. $\boldsymbol{E}$, Mouse brain sections were immunostained with rabbit lgG (I, negative control), appoptosin antibody (II, IV, and V), or the appoptosin antibody pre-incubated with the antigen peptide for competition (III), then incubated with biotinylated secondary antibody and ABC Elite reagent, developed with DAB substrate, and visualized under a light microscope to observe hippocampal and cortical neurons. Scale bars: (in I) I-III, $400 \mu \mathrm{m}$; (in IV) IV-V, $50 \mu \mathrm{m}$. $\boldsymbol{F}$, Human brain cortical sections were subjected to immunohistochemistry as in $\boldsymbol{E}$. Scale bar, $50 \mu \mathrm{m}$. G, SY5Y cells were fractionated into mitochondria (P) and cytosol (S) fractions. Equal amounts of protein lysates were immunoblotted for appoptosin, $\alpha$-tubulin (indicative of cytosol), and COXIV (indicative of mitochondria). $\boldsymbol{H}$, Human brain cortical sections were immunostained with antibodies against appoptosin and COX IV, incubated with secondary antibodies conjugated with Alexa Fluor 488 or 594 , counterstained with DAPI, and visualized under a fluorescence microscope. Scale bar, $25 \mu \mathrm{m}$.

secondary antibodies conjugated with Alexa Fluor 488 or 594, counterstained with DAPI, and visualized under a fluorescence microscope. For neurotoxicity studies, mouse cortical primary neurons were first infected with EGFP-containing lentivirus expressing mock or appoptosin RNAi for $48 \mathrm{~h}$, and treated with $\mathrm{A} \beta_{1-42}$ or glutamate for another $24 \mathrm{~h}$. Neurons were then fixed, permeabilized, incubated sequentially with cleaved caspase-3-specific antibody and Alexa Fluor 594-conjugated secondary antibody plus DAPI, and visualized under a fluorescence microscope.

ROS activity assay. After transfection with appoptosin cDNA, HEK293T cells were incubated with $10 \mu \mathrm{m} \mathrm{CM}-\mathrm{H}_{2} \mathrm{DCFDA}$ at $37^{\circ} \mathrm{C}$ for $10 \mathrm{~min}$. Cells were then subjected to flow cytometry analysis after the addition of $5 \mu \mathrm{g} / \mathrm{ml}$ PI and PI-negative populations were gated for analysis of dye intensity to indicate ROS activity.

RNA interference. Stealth RNAi for appoptosin (targeting sequence agacgctcatgttacacccagtgat, corresponding to nucleotides 119-143 of mouse Slc25a38 CDS; NCBI Reference sequence: NM_144793.1) and negative control RNAi were synthesized and provided by Invitrogen. Stealth RNAi was delivered into cells using Lipofectamine RNAi MAX (Invitrogen). Lentiviral shRNA for appoptosin (targeting sequence aacccgtctgcaggccctg, corresponding to nucleotides 216-234 of mouse Slc25a38 CDS; NCBI Reference sequence: NM 144793.1) or mock shRNA (scrambled) was constructed into a pLVTHM vector. Viruses were packaged in HEK293T cells and stored in HBSS at $-80^{\circ} \mathrm{C}$ before use. 
RNA extraction, reverse transcription and quantitative PCR. Total RNA was extracted from cells using the TRIzol Reagent (Invitrogen). Reverse transcription was performed using SuperScript III First-Strand Synthesis kit for quantitative reverse transcription PCR (Invitrogen). The same amounts of cDNA from each group of samples were used for real-time PCR with primers for appoptosin (forward: $5^{\prime}$ AGCAGTATTTCTTGCGAGG-3' reverse: $5^{\prime}$ AGGAGAGTTGCTGTCAGG-3') and primers for glyceraldehyde 3-phosphate dehydrogenase (GAPDH) (forward: 5'-CCCTTCATTG ACCTCAACTA- $3^{\prime}$, reverse: $5^{\prime}$-CCTTCTCCAT GGTGGTGAA-3'). Quantitative PCR was performed and analyzed by Bio-Rad MyIQ single color real-time PCR detection system.

Transient focal cerebral ischemia. Male Sprague Dawley rats weighing 250-300 g were housed in a $12 \mathrm{~h}$ light/dark cycle and given free access to food and water. These rats were subjected to middle cerebral artery occlusion (MCAO). Briefly, rats were anesthetized by isoflurane and the right middle cerebral artery was intraluminally occluded with a 3.0 monofilament suture to induce transient focal cerebral ischemia. After $2 \mathrm{~h}$ of MCAO, the filament was removed for reperfusion for different time periods before the rats were killed. The brains were collected, coronally sectioned, and stained with triphenyl tetrazolium chloride to visualize the ischemic regions. Alternatively, the ischemic cortex was dissected from the ipsilateral hemisphere and the control cortex was dissected from the nonischemic hemisphere and these cortical samples were lysed for Western blot analyses.

Mitochondrial fragmentation assay. Mouse primary neuronal cells cultured for $10 \mathrm{~d}$ were infected with mock or appoptosin RNAi lentivirus. After $48 \mathrm{~h}$, pmito-DsRed2, which targets mitochondria, was introduced for another $48 \mathrm{~h}$ before addition of conditioned media containing $\mathrm{A} \beta$ oligomers or $100 \mu \mathrm{M}$ monosodium glutamate. Cells were visualized by deconvolution microscopy with $3 \mathrm{D}$ reconstruction $48 \mathrm{~h}$ after neurotoxicity treatment. Volocity software (Improvision) was used for quantification of mitochondrial length and number as described previously (Barsoum et al., 2006).

Appoptosin levels in human brains. Brain cortical region samples from $\mathrm{AD}$ patients and controls were kindly provided by Dr. Y. Shen. Brain cortical region samples from in-

farct patients and controls were from the University of California, San Diego. Information for these patients and controls are listed in Table 1. Samples were lysed in radioimmunoprecipitation assay buffer. Equal protein amounts of cell lysates were subjected to SDS-PAGE and Western blot.

Heme assay. Cellular heme concentrations were measured based on a fluorescence assay in which iron is removed by heating in a strong oxalic acid solution and the resultant protoporphyrin is measured by fluorescence (Sinclair et al., 2001). Briefly, cells were washed with DPBS and lysed in CelLytic M Cell Lysis Reagent (Sigma). Cell lysates containing 40 $\mu \mathrm{g}$ of protein were added into $1 \mathrm{ml}$ of saturated oxalic acid solution $(\sim 1$ $\mathrm{M}$ at room temperature) and mixed well. Five hundred microliters of mixed samples were allocated as blank controls and the rest of the samples were heated at $98^{\circ} \mathrm{C}$ for $30 \mathrm{~min}$ and cooled to room temperature. The samples and blank controls were transferred into 96-well plates $(200 \mu \mathrm{l}$
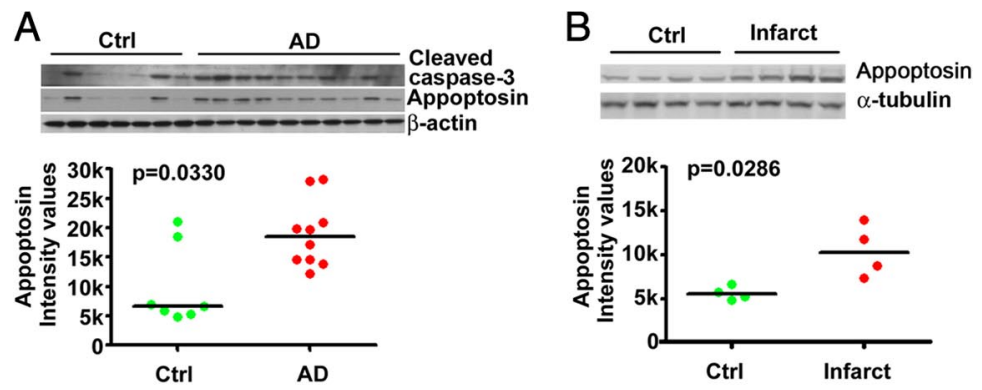

E
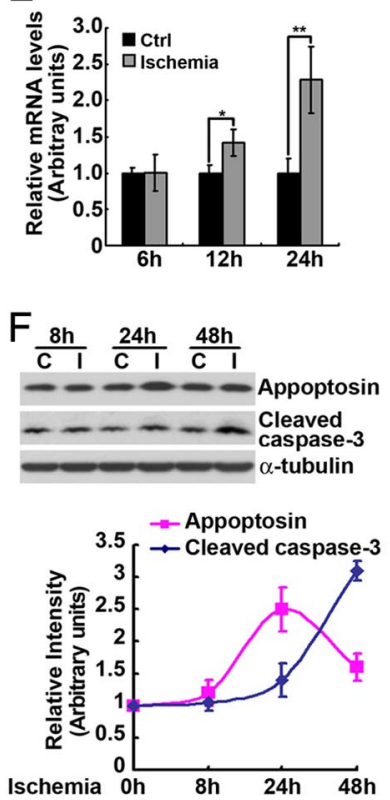

Figure 2. Appoptosin is involved in neurodegeneration. $A$, Equal amounts of protein lysates from the brains of AD patients and controls were immunoblotted for appoptosin and cleaved caspase-3. Protein levels were quantitated by densitometry for statisntrols were immunoblotted for appoptosin. Protein levels were quantitated for statistical comparison. Bottom, Bars are median values. $C$, Rat primary neurons were treated with $10 \mu \mathrm{mA} \beta_{1-42}$ for the indicated time points. Total RNAs were extracted, reverse ith control (4 h untreated, set as 1 a.u.). $N=4,{ }^{*} p<0.05 ;{ }^{* *} p<0.01 ;{ }^{* * *} p<0.001$. D, Rat primary neurons were treated as C. The protein levels of appoptosin and cleaved caspase- 3 were detected by Western blot, quantified using densitometry Sprague Dawley rats were subjected to MCAO for $2 \mathrm{~h}$, followed by reperfusion for the indicated time points. RNAs extracted from ischemic cortical regions and the corresponding control (Ctrl) cortical regions in the other hemisphere were reverse transcribed and

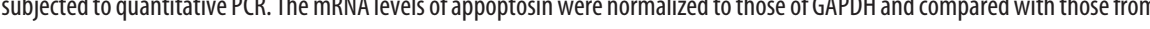
lysates from the ischemic $(I)$ cortical regions were compared with those from the corresponding control $(C)$ cortical regions in the other hemisphere for levels of appoptosin and cleaved caspase-3. Error bars indicate SD.

for each well, duplicates for each sample). Fluorescence of porphyrin was read at $400 \mathrm{~nm}$ for excitation and $662 \mathrm{~nm}$ for emission.

Mitochondrial membrane potential assay. A mitochondrial membrane potential (MMP) kit (Invitrogen) was used to measure MMP. Briefly, cells were transfected with appoptosin for $24 \mathrm{~h}$, or incubated with $5 \mathrm{~mm} \mathrm{mCCCP}$ and incubated at $37^{\circ} \mathrm{C}$ in the dark for $15 \mathrm{~min}$ (as a positive control). Cells were then incubated with Mito Tracker Red (50 nM final concentration) in culture medium for $30 \mathrm{~min}$ at $37^{\circ} \mathrm{C}$. Cells were washed with PBS and trypsinized. After two additional washes in ice-cold PBS, stained cells were analyzed by flow cytometry. MPP was indicated by the intensity of fluorescence measured at 585 $\mathrm{nm}$ emission.

Statistical analysis. Selection of statistical tests was determined by the GraphPad Prism 5 software. Two-tailed Mann-Whitney nonparametric test was used for all analyses. 
A

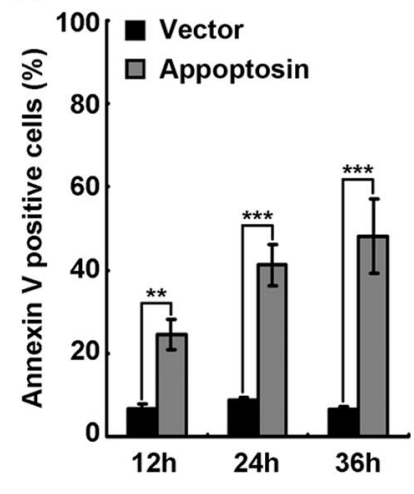

C

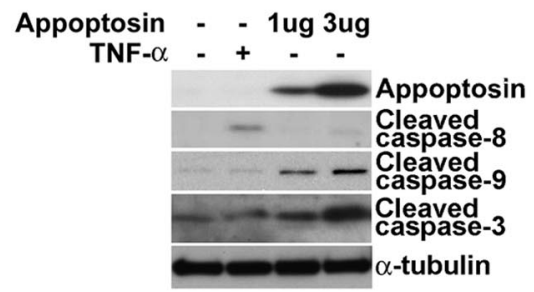

E

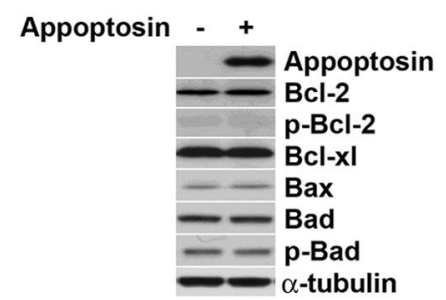

Figure 3. Overexpression of appoptosin induces intrinsic caspase-dependent apoptosis. $\boldsymbol{A}$, HEK293T cells transfected with appoptosin were collected at indicated time points, stained with Annexin V-FITC, and analyzed by FACS. The percentage of Annexin V-positive (apoptotic) cells was quantitated. $N=7,{ }^{* *} p<0.01 ;{ }^{* * *} p<0.001$. B, HEK293T cells were transfected with appoptosin or control vector for $24 \mathrm{~h}$. Cells were fractionated into mitochondria $(P)$ and cytosol $(S)$ fractions. Equal amounts of protein lysates were immunoblotted for appoptosin, total cytochrome c (Cyto-C), AIF, Endo G, $\alpha$-tubulin (indicative of cytosol), and COX IV (indicative of mitochondria). C, HEK293T cells were transfected with different amounts of appoptosin or control vector ( - ). Some control vector-transfected cells were also treated with $25 \mathrm{ng} / \mathrm{ml}$ TNF- $\alpha$ for $24 \mathrm{~h}$ (to activate caspase-8). Cell lysates were immunoblotted for cleaved caspase-8, caspase-9, and caspase-3. D, HEK293T cells were transfected with appoptosin for $6 \mathrm{~h}$ and then treated with $50 \mu \mathrm{m} Z$-VAD or $25 \mu \mathrm{m} \mathrm{DPQ}$ for $24 \mathrm{~h}$. Cells were stained with Annexin V-FITC and analyzed by FACS. $N=4,{ }^{*} p<0.05$. $\boldsymbol{E}$, HEK293T cells were transfected with appoptosin and cell lysates were immunoblotted for BCl-2, Bcl-xl, Bax, Bad, and phosphorylated (p) Bcl-2 and Bad.

\section{Results}

Appoptosin is identified as an APP/AICD-interacting protein We performed yeast-two-hybrid assays to screen a human fetal cDNA library using AICD (or C57, the last 57 aa of APP's C terminus) as the bait. We identified a positive clone containing a partial cDNA sequence of a mitochondrial solute carrier family (SLC25) protein, SLC25A38 (which we named appoptosin). In addition, we found that coexpression of full-length appoptosin cDNA with AICD/C57 in yeast resulted in dramatically increased $\beta$-gal activity, indicating an interaction between the two (Fig. 1A). Interaction between overexpressed appoptosin and AICD/C57 was confirmed in mammalian cells by coimmunoprecipitation studies (Fig. $1 B$ ). In addition, we found that appoptosin can interact with full-length APP and APP $\beta$-CTF/C99, but not with a truncated form of APP lacking the entire AICD/C57 domain (APP $\Delta$ C57) (Fig. $1 B$ ), confirming the necessity of the AICD/C57 domain for APP-appoptosin interaction. In addition, a truncated form of APP lacking the last 14 aa (APP $\Delta$ C14) still interacted with appoptosin (Fig. $1 B$ ), suggesting that the last 14 aa of APP is not important for its interaction with appoptosin. It appears that appoptosin has a much higher binding affinity to C99 or C57 than to full-length APP (Fig. 1B). While the definitive proof awaits further investigation, a possible explanation could be that after cleavage by secretases, the resulting APP C-terminal fragments underwent some conformational changes or modifications in the AICD/C57 domain such that the ectodomain lacking APP variants or C57 can bind more tightly to appoptosin. Finally, we confirmed the interaction between endogenous appoptosin and endogenous APP in human neuroblastoma SY5Y cells (Fig. 1D).

Appoptosin is highly abundantly expressed in blood cells (Guernsey et al., 2009). To explore its potential involvement in heme synthesis and neurodegeneration in neurons, we performed immunohistochemistry analysis and found that appoptosin was also expressed in the hippocampal and cortical neurons of mice (Fig. $1 E$ ) and humans (Fig. 1F). Appoptosin belongs to the mitochondrial solute carrier family whose members are encoded by the nuclear genome. These proteins are synthesized in the cytoplasm and then translocated to the mitochondrial inner membrane through a mechanism involving the TOM70 and TIM22 complexes (Pfanner and Geissler, 2001). We found that appoptosin was coseparated with the mitochondrial marker COX IV (Fig. 1G), confirming its mitochondrial localization. Immunofluorescent staining of appoptosin in human cortical neurons (Fig. $1 \mathrm{H}$ ) also showed that appoptosin is localized in the mitochondria.

\section{Appoptosin is involved in neuronal death associated with neurodegeneration}

Since APP plays an essential role in AD and many APP-binding proteins have been found to be involved in the $\mathrm{AD}$ pathological process, we examined the level of appoptosin in the brain of $\mathrm{AD}$ patients and found it dramatically increased when compared with that of controls (Fig. 2A). Notably, the level of appoptosin correlated very well with the level of cleaved/activated caspase-3, which was also increased in the brain of $\mathrm{AD}$ patients (Louneva et al., 2008) (Fig. 2A). In addition, we found that the level of appoptosin was markedly increased in the brain of infarct patients when compared with that of controls (Fig. 2B). To study whether the increased level of appoptosin in $\mathrm{AD}$ and infarct patients is caused by neurotoxic insults in these diseases (i.e., $\mathrm{A} \beta$ in $\mathrm{AD}$ and the ischemia condition in infarct), we treated primary cultures of rodent neurons with $\mathrm{A} \beta_{1-42}$ at different time points and observed that both the mRNA (Fig. 2C) and protein (Fig. 2D) levels of appoptosin were significantly increased upon $\mathrm{A} \beta$ treatments along with activation of caspase- 3 ; however, the upregulation of appoptosin clearly precedes 
caspase-3 activation (Fig. 2D). Similarly, in rodent stroke models subjected to MCAO to create focal ischemia, the brain mRNA (Fig. $2 E$ ) and protein (Fig. $2 F$ ) levels of appoptosin were elevated, followed by the activation of caspase- 3 (Fig. 2F). These results strongly suggest that upregulation of appoptosin is an early event in the cascade of pathological processes leading to neuronal death in neurodegeneration.

\section{Appoptosin is a novel pro-apoptotic protein and regulates intrinsic caspase-dependent apoptosis}

Upon overexpression of appoptosin, we found a significant level of cell apoptosis as determined by Annexin V staining (Fig. 3A). Moreover, we found that overexpression of appoptosin resulted in release of cytochrome $c$ from mitochondria into the cytosol (Fig. 3B). Since caspase-independent apoptosis involves the release of apoptosis-inducing factor (AIF) and endonuclease G (Endo G) from mitochondria (Hail et al., 2006), we also examined the effect of appoptosin on them and found that overexpression of appoptosin did not activate the release of AIF or Endo $\mathrm{G}$ at $24 \mathrm{~h}$ after transfection (Fig. $3 B$ ), when cells have already experienced cytochrome $c$ release and dramatic apoptosis (Fig. 3A). However, there was some release of AIF and Endo G at later stages after transfection of appoptosin, probably due to the loss of mitochondrial membrane integrity during late apoptotic stages or the activation of caspases as mitochondrial release of AIF and Endo G may require caspase activation under certain conditions (Arnoult et al., 2003). Overexpression of appoptosin also induced activation of caspase-9 and caspase- 3 but not caspase- 8 (Fig. $3 C$ ). When cells were treated with Z-VAD, a general caspase inhibitor, the pro-apoptotic effect of appoptosin was significantly reduced (Fig. 3D). In contrast, $\mathrm{DPQ}$, an inhibitor of poly(ADP-ribose) polymerase that mediates caspase-independent cell death (Yu et al., 2002), failed to reduce the apoptosis induced by overexpression of appoptosin (Fig. 3D). Together, these results suggest that overexpression of appoptosin induces apoptosis through an intrinsic caspase-dependent pathway.

The Bcl-2 family of proteins plays an important role in apoptosis and may participate in neurodegeneration (Cory and Adams, 2002). Our results showed that overexpression of appoptosin did not affect the protein levels or phosphorylation of certain Bcl-2 family members (Fig. $3 E$ ), including the pro-apoptotic Bax, whose expression has been reported to be increased in the brain of $\mathrm{AD}$ patients (Su et al., 1997). Interestingly, we found that when the level of appoptosin was downregulated by RNAi (Fig. 4A), Baxinduced apoptosis was dramatically inhibited (Fig. $4 B$ ), whereas apoptosis induced by overexpression of appoptosin was not affected when the level of Bax was downregulated (Fig. 4C). These results suggest that Bax is upstream from the appoptosincaspase-3.
B
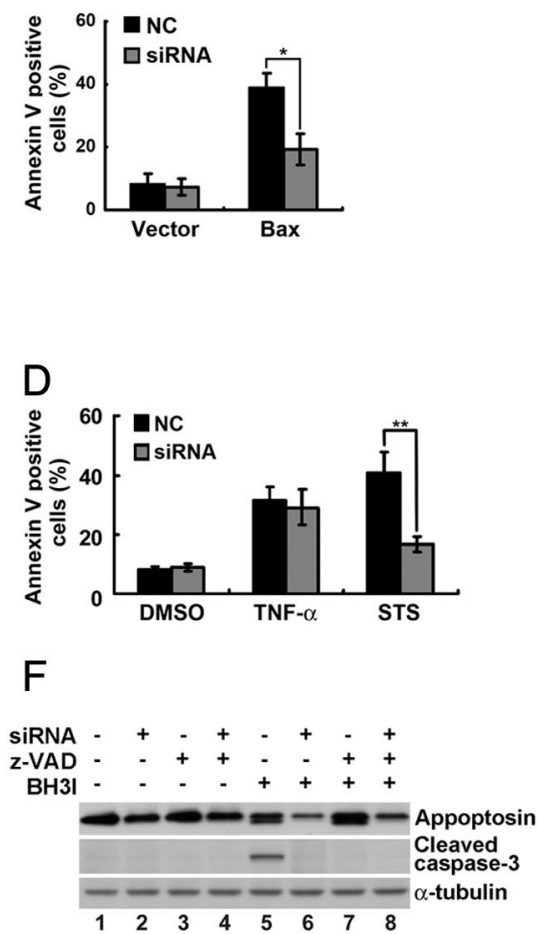

MSO
-VAD

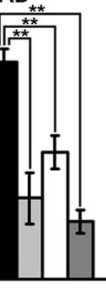

Bax

Cleaved

$\alpha$-tubulin

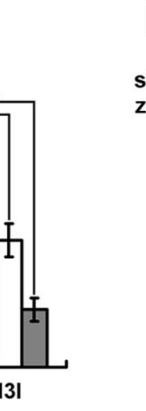

.

Figure 4. Downregulation of appoptosin inhibits Bcl-2 family member-dependent apoptosis. $\boldsymbol{A}$, Appoptosin stealth siRNA or nelrol (NC) siRNA was transfected into N2a cells for $72 \mathrm{~h}$. Appoptosin mRNA levels were analyzed by reverse transcrip/quantitative PCR and normalized to those of GAPDH. Appoptosin and $\alpha$-tubulin protein levels were analyzed by Western blot. C, N2a cells were first transfected with Bax siRNA or control siRNA for $24 \mathrm{~h}$. After equal splitting and incubation for $24 \mathrm{~h}$, cells were transfected with appoptosin for another $24 \mathrm{~h}$. Cell lysates were analyzed for Bax, appoptosin, and cleaved caspase-3. D, Cells were transfected with appoptosin siRNA or NC siRNA for $48 \mathrm{~h}$ and then treated with dimethylsulfoxide (DMSO; as control), $25 \mathrm{ng} / \mathrm{ml}$ TNF- $\alpha$ plus $1 \mu \mathrm{m}$ cycloheximide for another $12 \mathrm{~h}$, or $0.05 \mu \mathrm{m}$ staurosporine (STS) for another $24 \mathrm{~h}$. Cells were stained with Annexin

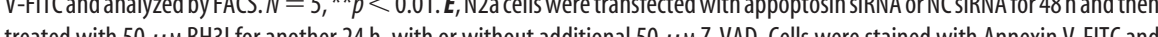
analyzed by FACS. $N=5,{ }^{* *} p<0.01$. $\boldsymbol{F}$, N2a cells were treated as in $(\boldsymbol{E})$, and cell lysates were analyzed for appoptosin and cleaved

mediated apoptotic pathway. Downregulation of appoptosin also prevented staurosporine-induced apoptosis, known to activate the intrinsic apoptotic pathway (Belmokhtar et al., 2001), but had no effect on cell death in HEK293T cells induced by TNF- $\alpha$, which mainly triggers the extrinsic apoptotic pathway without affecting the intrinsic apoptotic pathway in this cell line (Rath and Aggarwal, 1999) (Fig. 4D). Moreover, apoptosis induced by BH3I, a BH3 domain-mimicking chemical that disrupts interactions between pro-apoptotic and anti-apoptotic members of the Bcl-2 family (Degterev et al., 2001), was significantly reduced upon downregulation of appoptosin (Fig. 4E). Activation of caspase- 3 by BH3I treatment was also inhibited by downregulation of appoptosin (Fig. $4 F$ ). In addition, BH3I treatments led to the appearance of a doublet of appoptosin immunoreactive bands, implying proteolytic cleavage of appoptosin, possibly by caspases (Fig. $4 F$ ), which is an observation that warrants further investigation. Together, these results suggest that appoptosin is an important mediator in $\mathrm{Bcl}-2$ protein family-regulated apoptosis. 
A
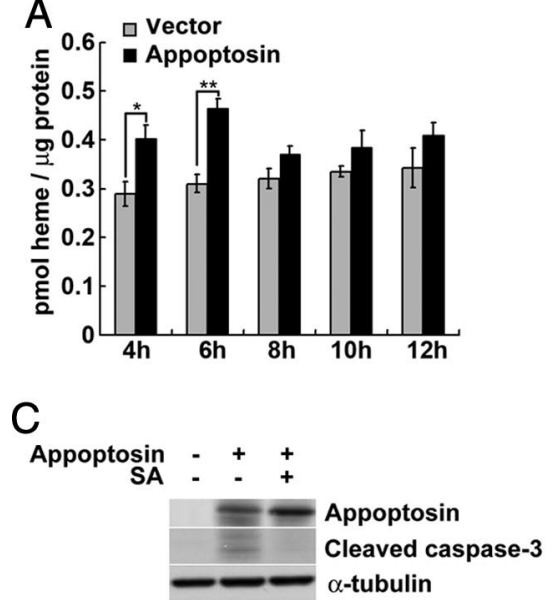

$E$

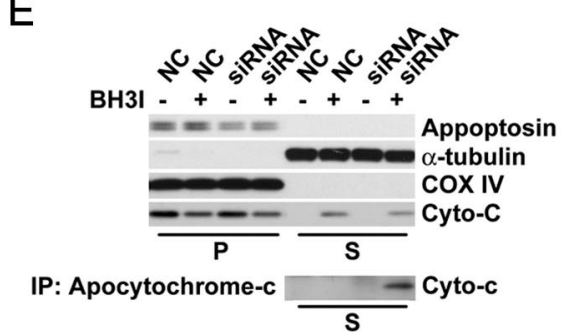

G

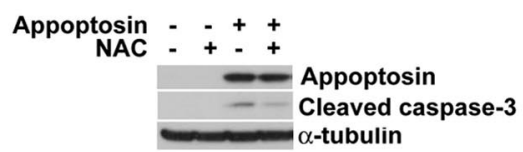

B
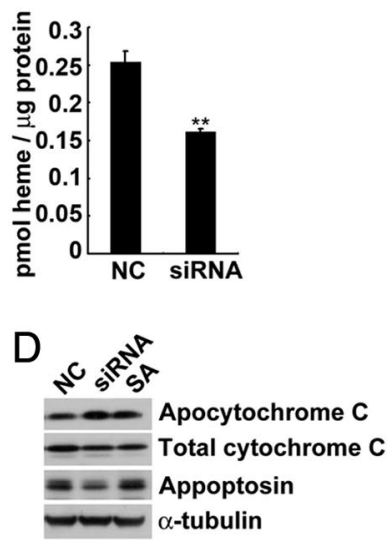

$\mathrm{F}$
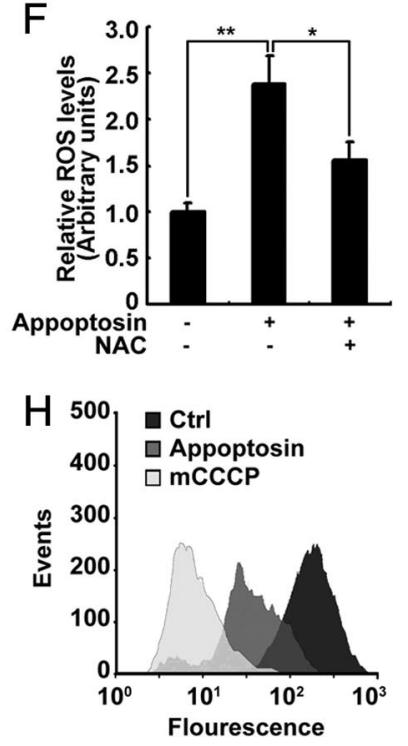

Figure 5. Appoptosin induces apoptosis through regulating heme synthesis. $A, N 2$ a cells transfected with appoptosin or control vector were collected at indicated time points and assayed for cellular heme levels. $N=5,{ }^{*} p<0.05,{ }^{* *} p<0.01 . B$, N2a cells were transfected with appoptosin stealth siRNA or negative control (NC) siRNA for $72 \mathrm{~h}$ and assayed for cellular heme levels. $N=4$, ${ }^{* *} p<0.01$. C, Cells were pretreated with or without $1 \mu \mathrm{M} S A$ for $12 \mathrm{~h}$ and then transfected with appoptosin for $24 \mathrm{~h}$, in the presence/absence of SA. Cell lysates were analyzed for appoptosin and cleaved caspase-3. D, SY5Y cells were transfected with appoptosin siRNA or NC siRNA for $72 \mathrm{~h}$, or treated with $1 \mu \mathrm{m}$ SA for $36 \mathrm{~h}$. Cell lysates were assayed for appoptosin, total cytochrome cand $\alpha$-tubulin by Western blot, and assayed for apocytochrome c by immunoprecipitation-Western blot. $E$, Cells were transfected with appoptosin siRNA or NC siRNA for $48 \mathrm{~h}$, and treated with $(+)$ or without $(-) 50 \mu \mathrm{m} \mathrm{BH3l}$ for another $24 \mathrm{~h}$. Cells were then fractionated into mitochondria (P) and cytosol (S) fractions. Equal amounts of protein lysates from each fraction were immunoblotted for appoptosin, total cytochrome c (Cyto-C), $\alpha$-tubulin (indicative of cytosol), and COX IV (indicative of mitochondria) Apocytochrome c in cytosolic fractions was assayed by immunoprecipitation (IP) and Western blot. $F$, Cells were transfected with appoptosin or control vector for $24 \mathrm{~h}$. Cells were then loaded with $10 \mu \mathrm{m}$ 2,7-dichlorodihydrofluorescein diacetate and analyzed by FACS to measure the levels of ROS. Some appoptosin-transfected cells were concomitantly treated with $20 \mu \mathrm{m} \mathrm{NAC} \mathrm{including} \mathrm{a} 2 \mathrm{~h}$ pretransfection treatment. $N=5,{ }^{*} p<0.05,{ }^{* *} p<0.01$. G, Cells were pretreated with $20 \mu \mathrm{m} \mathrm{NAC} \mathrm{for} 2 \mathrm{~h}$ and then transfected

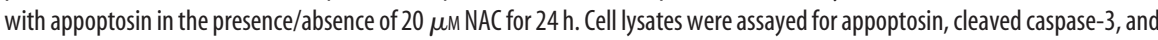
$\alpha$-tubulin. $\boldsymbol{H}$, Cells transfected with appoptosin were incubated with Mito Tracker Red (50 nм final concentration) in culture medium for $30 \mathrm{~min}$ at $37^{\circ} \mathrm{C}$. Cells were then washed and measured for fluorescence intensity at $585 \mathrm{~nm}$ emission by FACS. Cells

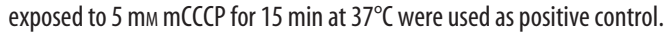

Appoptosin regulates apoptosis by governing heme synthesis Recent studies suggested that appoptosin may function as a transporter of glycine/ $\delta$-ALA, which is crucial for heme synthesis (Guernsey et al., 2009). To study whether heme is involved in appoptosin-induced apoptosis, we overexpressed appoptosin and measured cellular levels of heme. A transient elevation of heme was observed shortly after transfection with appoptosin plasmid, during which time exogenous appoptosin was found to be expressed and later disappeared (Fig. 5A). Restoration of the cellular heme level may be attributed to the scavenging mechanism that clears toxic molecules. We speculate that the transient increase in heme level is sufficient to activate a cascade of events leading to apoptosis. Downregulation of appoptosin resulted in a modest but statistically significant decrease of cellular heme (Fig. 5B). When cells were treated with succinylacetone (SA), a heme synthesis inhibitor that inactivates ALA dehydratase, overexpression of appoptosin failed to induce caspase3 activation (Fig. 5C). Furthermore, downregulation of appoptosin increased the level of heme-free apocytochrome $c$, which can prevent apoptosome formation, caspase- 9 activation, and Bax-induced apoptosis (Martin and Fearnhead, 2002; Martin et al., 2004; Hail et al., 2006) without affecting the total level of cytochrome $c$ (Fig. 5D). In cells treated with BH3I, although downregulation of appoptosin did not inhibit release of cytochrome $c$ into the cytosol, the released cytochrome $c$ contained apocytochrome $c$ (Fig. 5E). Since excessive heme may promote the generation of toxic ROS, we also measured the level of ROS and found that it was indeed increased upon overexpression of appoptosin (Fig. 5F), whereas treatments with an ROS scavenger, NAC, inhibited the elevation of ROS (Fig. $5 F$ ) and activation of caspase-3 (Fig. 5G) resulting from appoptosin overexpression. Finally, overexpression of appoptosin resulted in an impaired mitochondrial membrane potential (Fig. $5 H$ ). Together, these results suggest that appoptosin regulates cell apoptosis through controlling heme synthesis.

\section{Downregulation of appoptosin protects} neuronal cells against neurotoxicity To determine whether appoptosin-regulated heme synthesis and apoptosis are responsible for neuronal cell death in $\mathrm{AD}$, we downregulated the level of appoptosin by RNAi in SY5Y cells and treated these cells with $\mathrm{A} \beta_{1-42}$ and glutamate. The results showed that such treatments dramatically increased heme levels in control cells but not in appoptosin-downregulated cells (Fig. $6 A)$. In addition, the upregulation of ROS levels induced by $\mathrm{A} \beta$ and glutamate treatments was dramatically reversed by downregulation of appoptosin (Fig. $6 B$ ) in a similar manner to that by SA treatment (Fig. 6C). Moreover, when cells were treated with $\mathrm{A} \beta_{1-42}$ or glutamate, the levels of appoptosin were markedly increased, accompanied by activation of caspase-3 (Fig. $6 D, E$, lanes 1 vs 3 ), while activation of caspase- 3 upon $A \beta_{1-42}$ and glutamate treatments was largely inhibited when the levels of appoptosin were downregulated (Fig. $6 D$, E, lanes 3 vs 4 ). Importantly, fluorescent staining showed that $\mathrm{A} \beta_{1-42}$ and glutamate treat- 
A

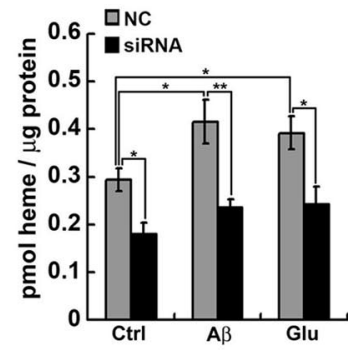

D
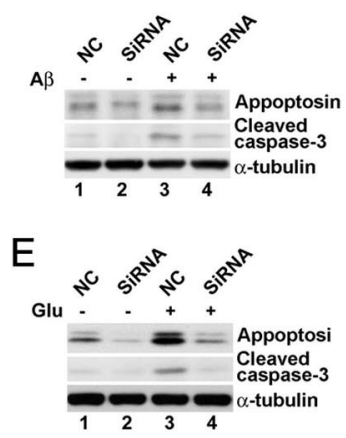

G

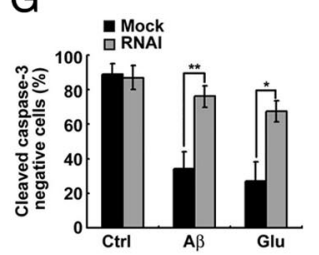

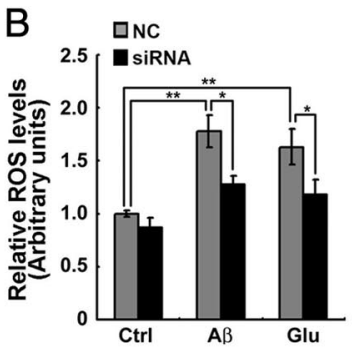

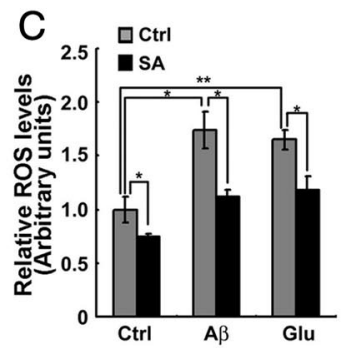

F $\quad$ EGFP
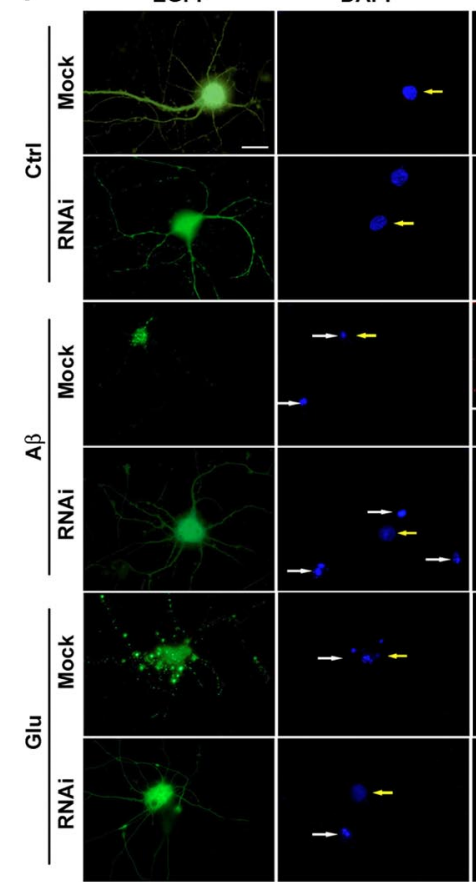

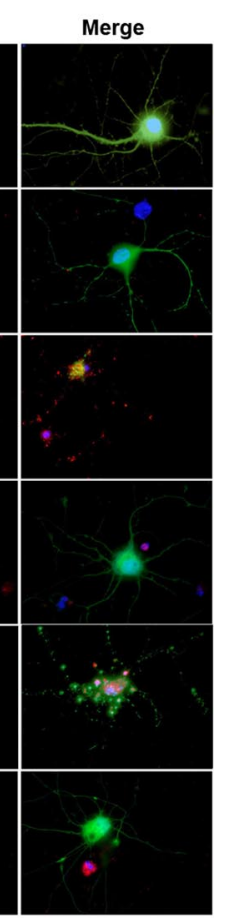

Figure 6. Downregulation of appoptosin rescues neuronal impairment caused by neurotoxicity. SY5Y cells were transfected with appoptosin stealth siRNA or negative control (NC) siRNA for $48 \mathrm{~h}$, and then treated with $10 \mu \mathrm{m} \mathrm{A} \beta_{1-42}$ or $200 \mu \mathrm{m}$ glutamate for another $24 \mathrm{~h}$. Cell lysates were assayed for $(\boldsymbol{A})$ heme levels and $(\boldsymbol{B})$ R0S levels. $N=4$, ${ }^{*} p<0.05,{ }^{* *} p<0.01$. $\boldsymbol{C}$, Cells were treated with $10 \mu \mathrm{m} \mathrm{A} \beta_{1-42}$ or $200 \mu \mathrm{m}$ glutamate for $24 \mathrm{~h}$, in the presence or absence (Ctrl) of $1 \mu \mathrm{m} \mathrm{SA}$. Cells were then assayed for ROS levels. $N=4$, ${ }^{*} p<0.05$, ${ }^{* *} p<0.01$. Cells transfected with appoptosin siRNA or NC siRNA were treated with $(\boldsymbol{D}) 10 \mu \mathrm{mA} \beta_{1-42}$ and $(\boldsymbol{E}) 200 \mu \mathrm{m}$ glutamate for $24 \mathrm{~h}$. Cell lysates were immunoblotted for appoptosin, cleaved caspase-3, and $\alpha$-tubulin. $\boldsymbol{F}$, Mouse primary cortical neurons were infected with lentivirus expressing mock or appoptosin RNAi for $48 \mathrm{~h}$, and then treated with $10 \mu \mathrm{m} A \beta_{1-42}$ or $200 \mu \mathrm{m}$ glutamate for $24 \mathrm{~h}$. After fixation and permeabilization, neurons were incubated with cleaved caspase-3-specific antibody overnight and then with fluorescence-conjugated secondary antibody for $1 \mathrm{~h}$ and with DAPI for 5 min. Neurons were observed under a fluorescent microscope. Green indicates infected neurons. Blue indicates DAPI staining of nucleus. Red indicates immunoreactivity of cleaved caspase-3. Yellow arrows indicate infected neurons. White arrows indicate apoptotic neurons. G, Over 100 GFP-positive neurons in $\boldsymbol{F}$ were used to count the numbers of cleaved caspase-3-negative cells. ${ }^{*} p<0.05$, ${ }^{* *} p<0.01$.

ments resulted in neurite damage, nuclear condensation, and intensive immunoreactivity of cleaved caspase- 3 in mouse primary neurons, indicating neuronal apoptosis (Fig. $6 F$ ), while downregulation of appoptosin by RNAi (Fig. 7A) largely reversed such phenomena (Fig. $6 F, G$ ), confirming a key role for appoptosin in mediating neurodegeneration. Mitochondrial fragmentation indicative of mitochondrial impairment is an early event during apoptotic cell death and is associated with neurodegenerative diseases (Knott et al., 2008). Here we also found that neuronal mitochondrial fragmentation induced by naturally secreted $A \beta$ oligomers or glutamate was significantly reduced by downregulation of appoptosin (Fig. $7 B, C$ ).

\section{Membrane-associated APP regulates appoptosin-mediated apoptosis}

Because appoptosin interacts with APP/AICD, we examined whether APP is involved in appoptosin-mediated apoptosis. The results showed that overexpression of appoptosin-interacting
APP forms including full-length APP, APP $\Delta \mathrm{C} 14$, and APP C99 decreased the caspase- 3 activation induced by appoptosin overexpression, whereas overexpression of nonappoptosininteracting APP $\Delta$ C57 did not (Fig. $8 A$ ). However, although APP AICD/C57 also interacts with appoptosin, its overexpression had little effect on appoptosin-induced caspase-3 activation (Fig. $8 A$ ). Since full-length APP, APP $\Delta$ C14, and APP C99 are membrane associated, whereas APP C57 is membrane dissociative (Fig. 1C), we speculate that the membrane-anchored APP forms may function to retain appoptosin in the cytosol, and thus reduce transport to the mitochondria of the overexpressed appoptosin (which leads to excessive production of heme and apoptosis). When membrane-anchored APP is cleaved by $\gamma$-secretase, APPbound appoptosin is released together with APP C57/AICD and translocated to the mitochondria to exert its function. In support of this, a BiFC assay (Hu et al., 2002) for direct visualization of protein interactions in living cells confirmed that the interaction between appoptosin and full-length APP is mostly cytosolic and 
A

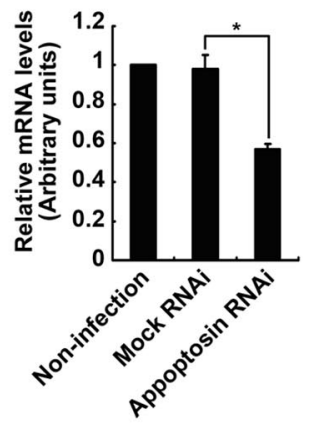

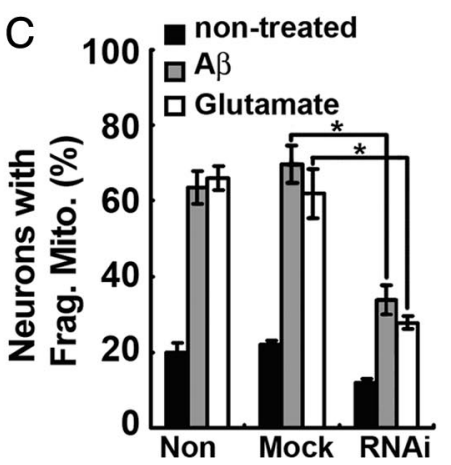

Glutamate
B

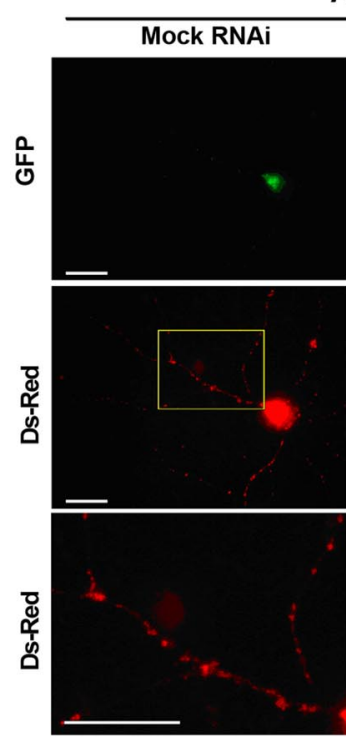

$\mathbf{A} \beta$

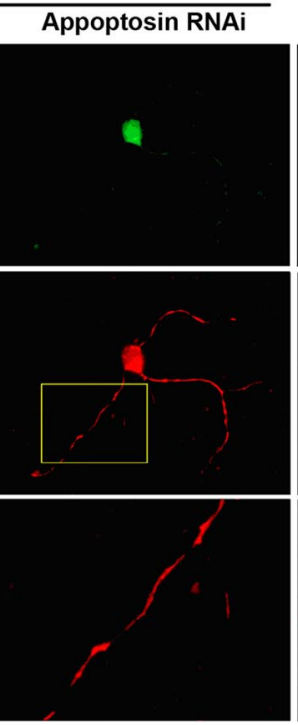

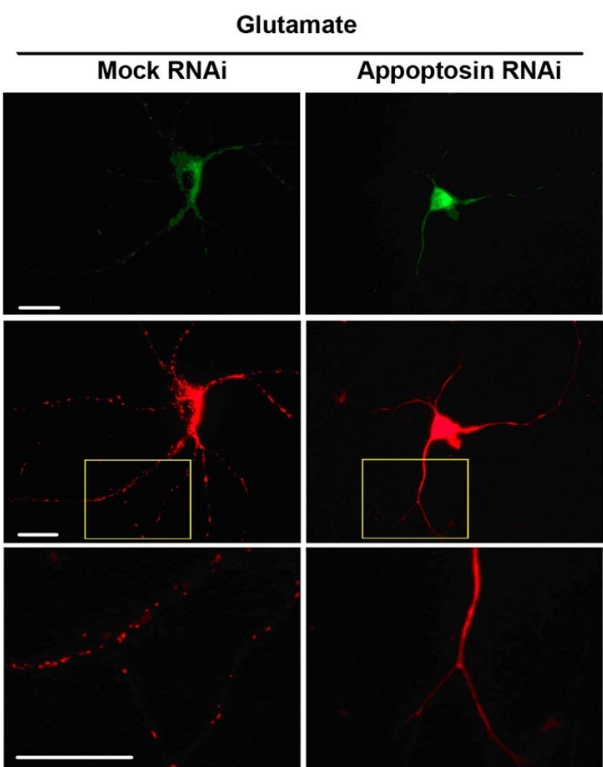

Figure 7. Downregulation of appoptosin rescues mitochondrial fragmentation caused by neurotoxicity. $\boldsymbol{A}$, Mouse primary neurons were infected with lentivirus expressing mock or appoptosin RNAi for $48 \mathrm{~h}$. Appoptosin mRNA levels were analyzed by reverse transcription/quantitative PCR, normalized to those of GAPDH, and compared with noninfected cell controls (set as 1 a.u.). $N=3$, ${ }^{*} p<0.05$. B, Mouse primary neurons were infected with mock or appoptosin RNAi lentivirus for $48 \mathrm{~h}$, transfected with pmito-DsRed2 for $48 \mathrm{~h}$, and treated with conditioned media containing $A \beta$ oligomers (left) or $100 \mu \mathrm{m}$ glutamate (right) for another $48 \mathrm{~h}$. Cells were then visualized under a deconvolution microscope. Green indicates infected neurons. Red indicates mitochondria. $\boldsymbol{C}$, For neurons treated in $\boldsymbol{B}$, the percentage of infected neurons with mitochondria fragmentation were quantified and compared. $N>100,{ }^{*} p<0.05$.

not mitochondrial, whereas the interaction between appoptosin and APP C57 is mainly in mitochondria, colocalized with Mito Tracker (Fig. $8 B, C$ ). Other supporting evidence came from the observation that although the total level of appoptosin was not affected, the level of appoptosin in mitochondria was markedly reduced upon overexpression of full-length APP, but not upon overexpression of APP $\Delta$ C57 (Fig. 8D). Together, these results suggest that appoptosin-induced apoptosis can be partially regulated by membrane-anchored APP.

\section{Discussion}

Dysregulation of apoptosis is involved in multiple diseases, including neurodegenerative disorders (Evan and Vousden, 2001; Kermer et al., 2004). Neurons, after suffering various insults, undergo apoptosis in neurodegenerative disorders (Kermer et al., 2004). Hence, targeting components of apoptotic pathways for inhibition may be neuroprotective, and identification of new factors involved in apoptosis will be important for disease intervention. Here we describe a novel pro-apoptotic protein, appoptosin, which induces intrinsic caspase-dependent apoptosis by altering heme synthesis and plays an essential role in the neuronal death associated with degenerative insults (Fig. 9). The Bcl-2 family members play crucial roles in apoptosis and are important therapeutic targets. Certain pro-apoptotic Bcl-2 family members, such as Bax, are increased in the brain of AD patients (Su et al., 1997). Here we have found that the levels of appoptosin are also increased in the brain of $\mathrm{AD}$ and infarct patients and that downregulation of appoptosin can inhibit Bax/ $\mathrm{BH} 3 \mathrm{I}$-induced apoptosis and $\mathrm{A} \beta /$ glutamate-induced neuronal death. Interestingly, a recent study found that the gene $M O B P$ is associated with progressive supranuclear palsy risk and showed that SNPs falling in or near MOBP are strongly correlated with appoptosin expression (Hoglinger et al., 2011). Therefore, appoptosin may be a key regulator in the pathogenesis of $\mathrm{AD}$ and other neurodegenerative diseases.

Appoptosin belongs to the SLC25 family, whose members are primarily located in the inner membrane of mitochondria and shuttle metabolites, nucleotides, etc., between the cytoplasm and mitochondrial matrix (Haitina et al., 2006). Because of their involvement in the maintenance of mitochondrial function, abnormalities in SLC25 members have been proposed as a factor in the pathogenesis of various diseases, including AD. However, direct experimental evidence is scarce (Kim-Han and Dugan, 2005). Herein, we demonstrate that perturbation of appoptosin contributes to disease pathogenesis. Appoptosin has been suggested as a trans- 
porter of glycine/ $\delta$-ALA across the mitochondrial inner membrane (Guernsey et al., 2009), a critical process in heme synthesis. Under homeostasis, the reactivity of heme is controlled by its insertion into the "heme pockets" of hemoproteins such as hemoglobin and cytochrome $c$. Hemoproteins have diverse biological functions including oxygen transport, electron transfer, etc. However, nonprotein-bound (free) heme is highly cytotoxic, probably due to the $\mathrm{Fe}$ atom contained within its protoporphyrin IX ring that can undergo Fenton reactions to catalyze the production of free radicals (Casella et al., 2002; Pamplona et al., 2007). Therefore, dysregulated cellular levels of heme, even subtle changes in the level of free heme, may promote deleterious cellular processes such as oxidative stress, overproduction of ROS, impairment of lipid bilayers and organelles, destabilization of the cytoskeleton, and inflammation (Ryter and Tyrrell, 2000; Atamna, 2004; Kumar and Bandyopadhyay, 2005). Heme metabolism has been found to be altered in many neurodegenerative disorders including $\mathrm{AD}$ (Ryter and Tyrrell, 2000; Atamna, 2004). In addition, it has been reported that heme oxygenase-1, a heme-degrading enzyme that scavenges excessive amounts of cellular heme, can protect cells against oxidative stress and may be a target for neuroprotection (Jazwa and Cuadrado, 2010). Here we have found that appoptosin regulates heme levels and inhibition of heme synthesis can abolish appoptosin-induced apoptosis, suggesting that appoptosin exerts its proapoptotic function through governing heme synthesis. Notably, we have found that downregulation of appoptosin does not affect BH3I-induced cytochrome $c$ release but rather reduces the level of heme contained in the released cytochrome $c$ to make them harmless, suggesting that normal heme synthesis is necessary for Bcl-2 family membermediated apoptosis.

We found that APP interacts with appoptosin through the AICD domain. APP/ AICD has been reported to interact with various intracellular proteins such as Fe65 and X11 through its YENPTY motif located between amino acids 682 and 687 (using APP 695 numbering), and the phosphorylation status of Tyr682 may affect the interaction of other proteins with APP (Borg et al., 1996; Biederer et al., 2002; Tamayev et al., 2009). However, we found that a truncated form of APP lacking the last 14 aa (APP $\Delta$ C14), including the YENPTY motif, still interacted with appoptosin (Fig. $1 B$ ), suggesting that different APP C-terminal motifs mediate its interaction with various intracellular proteins; and APP binds to appoptosin through the domain located between amino acids 639 and 681 (using APP 695 numbering).

APP is neuroprotective under physiological conditions and APP deficiency leads to various neuronal defects and renders
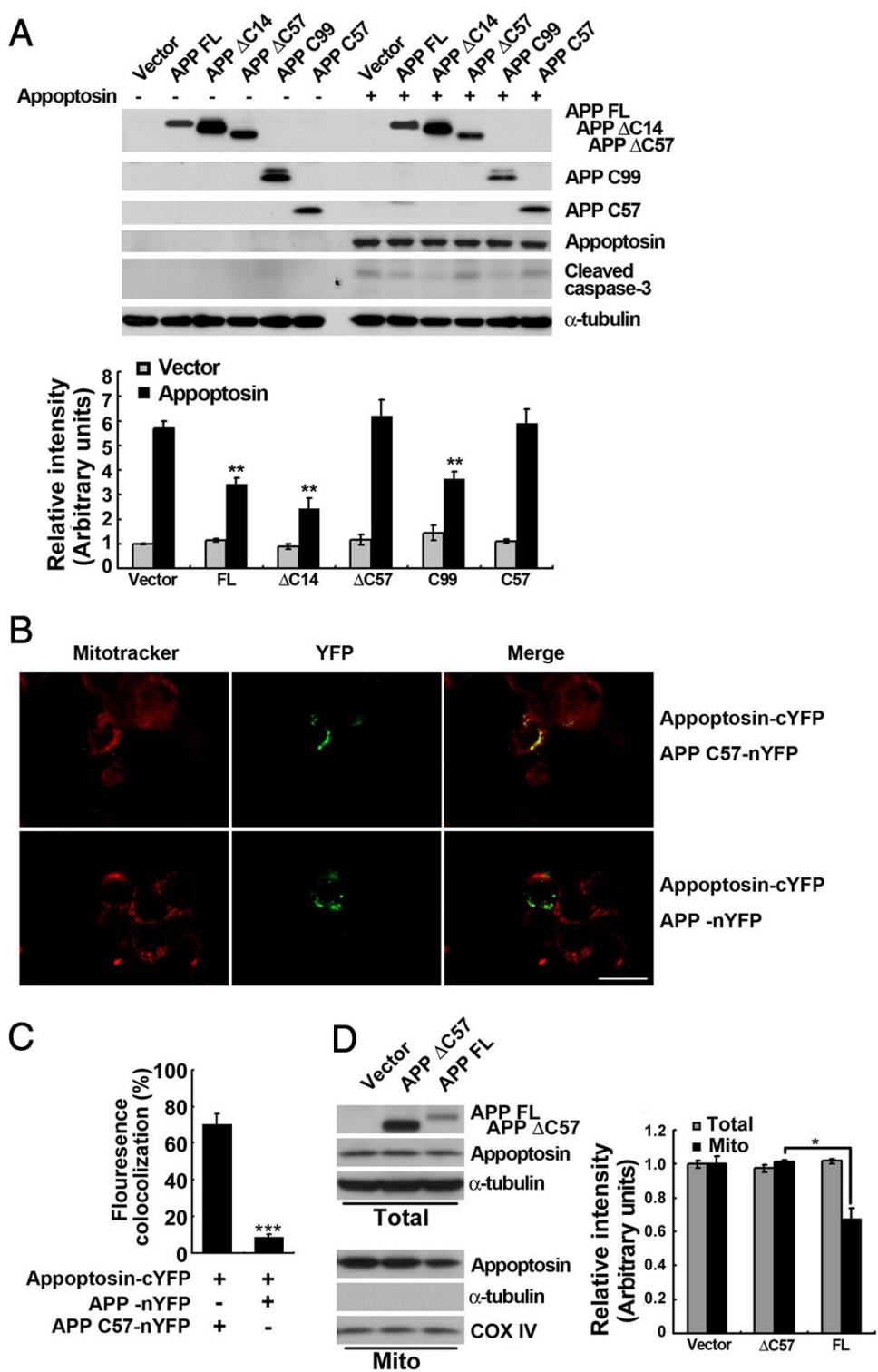

Figure 8. Membrane-associated APP regulates appoptosin-mediated apoptosis. A, Appoptosin was coexpressed with control or various APP form vectors in HEK293T cells. The levels of cleaved caspase-3 were analyzed by Western blot, quantified using densitometry, normalized to those of $\alpha$-tubulin, and compared with controls (the one transfected with vector alone, set as 1 a.u.). $N=5,{ }^{* *} p<0.01$. B, Appoptosin-cYFP was coexpressed with APP (57-nYFP or full-length APP-nYFP. Cells were stained with Mito Tracker for mitochondria (in red), and observed under a fluorescent microscope. Interaction was represented by the green fluorescence. Scale bar, $20 \mu \mathrm{m}$. $\boldsymbol{C}$, For cells treated in $\boldsymbol{B},>100$ cells showing green fluorescence indicative of interaction between appoptosin and APP/AICD were used to count the colocalization between green fluorescence and red fluorescence indicative of mitochondria. The numbers of cells showing yellow fluorescence indicative of APP-or AICD-appoptosin interaction in mitochondria were compared. ${ }^{* * *} p<0.001$. D, SY5Y cells were transfected first with empty vector, APPFL, or $\Delta$ C 57, and then with appoptosin. Cells were collected and mitochondria were extracted. The protein levels of appoptosin in total cell lysates and in mitochondrial fractions were detected by Western blot, quantified by densitometry, normalized to those of $\alpha$-tubulin or mitochondrial marker protein COX IV, and compared with those of controls (the one transfected with vector alone, set as 1 a.u.). $N=4{ }^{*} p<0.05$.

neurons more susceptible to apoptosis (Zheng et al., 1995; Han et al., 2005). Previous studies suggested that APP exerts its neuroprotective effect through the extracellular domain $\operatorname{SAPP} \alpha$ (Han et al., 2005; Ring et al., 2007; Ma et al., 2009). However, we found that APP C99, which lacks sAPP $\alpha$, but not APP $\Delta$ C57, contains $\operatorname{sAPP} \alpha$ and can reduce appoptosin-induced caspase activation, suggesting that APP inhibits appoptosin-induced apoptosis through its carboxyl domain rather than $\operatorname{sAPP} \alpha$. APP is synthesized in the endoplasmic reticulum and trafficked through the secretory pathway. Although there are studies suggesting that a 


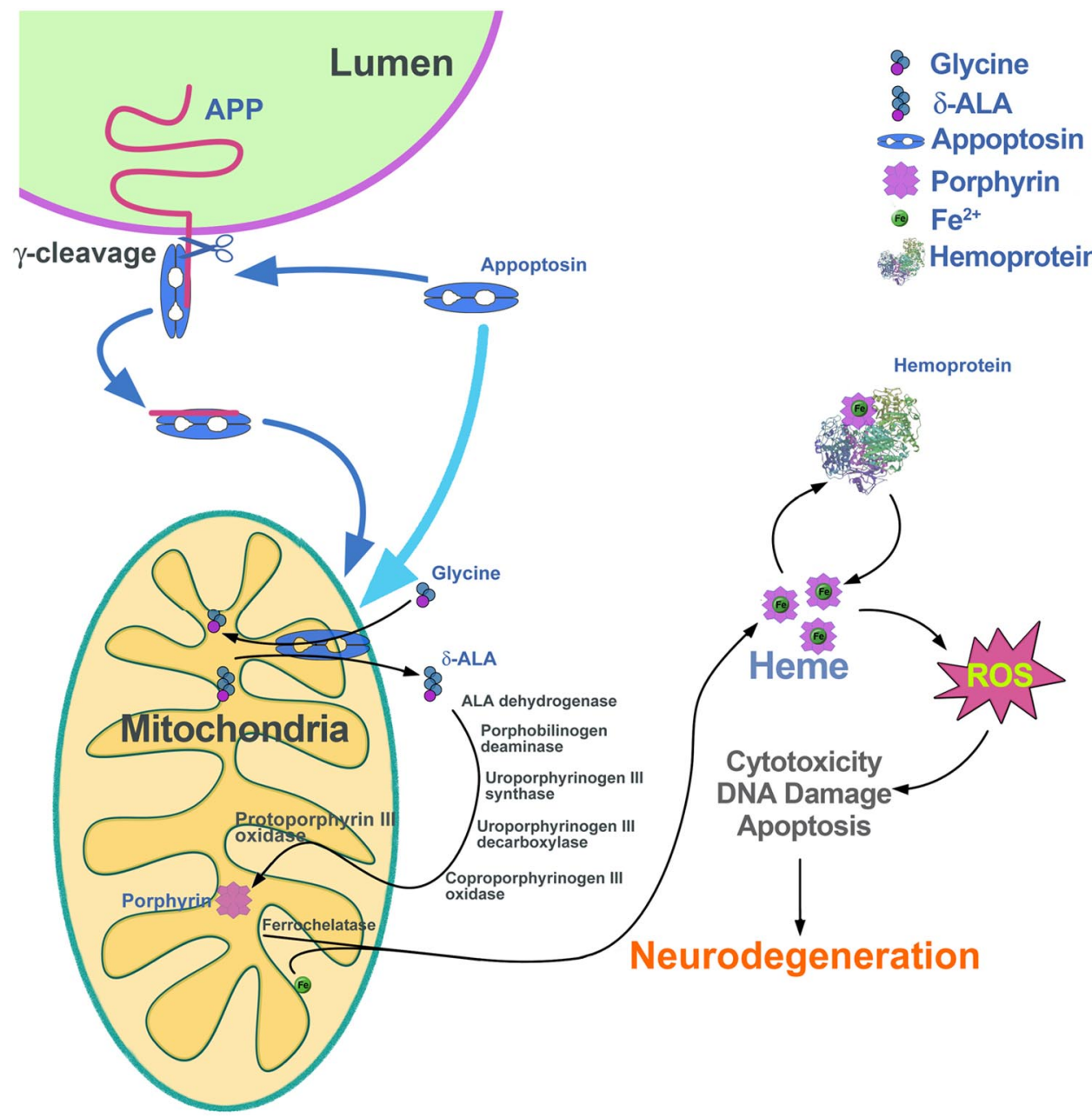

Figure 9. Scheme of appoptosin-mediated apoptotic pathway in neurodegeneration. Appoptosin is synthesized in the cytoplasm and then transported to the mitochondria. A part of appoptosin can interact with APP and thus is retained in the cytoplasm. Appoptosin mediates transport of $\delta$-ALA across the mitochondria membrane for heme synthesis. Upon neurotoxic insults, the levels of appoptosin are increased for more heme synthesis. Excessive heme, especially free heme, causes overproduction of ROS and cell toxicity and apoptosis, finally leading to neurodegeneration.

fraction of APP is localized in mitochondria (Anandatheerthavarada et al., 2003; Devi et al., 2006), this notion is not widely accepted and our results showed that an interaction between fulllength APP and appoptosin is not evident in mitochondria. Rather, our results suggest that membrane-anchored APP may interact with and retain a certain amount of appoptosin in the cytosol, through its AICD domain, thus keeping the level of appoptosin in mitochondria from being elevated for more heme production under certain insult stimulations or pathological conditions (Fig. 9). On the other hand, membrane-dissociated AICD has little effect on appoptosin-induced caspase activation, implying that following APP's cleavage by $\gamma$-secretase, the portion of appoptosin held by the membrane-associated APP forms can be released, together with AICD, and transported to mitochondria to increase heme synthesis and apoptosis.

\section{References}

Alves da Costa C, Sunyach C, Pardossi-Piquard R, Sévalle J, Vincent B, Boyer N, Kawarai T, Girardot N, St George-Hyslop P, Checler F (2006) Presenilindependent gamma-secretase-mediated control of p53-associated cell death in Alzheimer's disease. J Neurosci 26:6377-6385. CrossRef Medline

Anandatheerthavarada HK, Biswas G, Robin MA, Avadhani NG (2003) Mitochondrial targeting and a novel transmembrane arrest of Alzheimer's amyloid precursor protein impairs mitochondrial function in neuronal cells. J Cell Biol 161:41-54. CrossRef Medline

Arnoult D, Gaume B, Karbowski M, Sharpe JC, Cecconi F, Youle RJ (2003)
Mitochondrial release of AIF and EndoG requires caspase activation downstream of Bax/Bak-mediated permeabilization. EMBO J 22:4385-4399. CrossRef Medline

Atamna H (2004) Heme, iron, and the mitochondrial decay of ageing. Ageing Res Rev 3:303-318. CrossRef Medline

Barsoum MJ, Yuan H, Gerencser AA, Liot G, Kushnareva Y, Gräber S, Kovacs I, Lee WD, Waggoner J, Cui J, White AD, Bossy B, Martinou JC, Youle RJ, Lipton SA, Ellisman MH, Perkins GA, Bossy-Wetzel E (2006) Nitric oxide-induced mitochondrial fission is regulated by dynamin-related GTPases in neurons. EMBO J 25:3900-3911. CrossRef Medline

Belmokhtar CA, Hillion J, Ségal-Bendirdjian E (2001) Staurosporine induces apoptosis through both caspase-dependent and caspase-independent mechanisms. Oncogene 20:3354-3362. CrossRef Medline

Biederer T, Cao X, Südhof TC, Liu X (2002) Regulation of APP-dependent transcription complexes by Mint/X11s: differential functions of Mint isoforms. J Neurosci 22:7340-7351. Medline

Borg JP, Ooi J, Levy E, Margolis B (1996) The phosphotyrosine interaction domains of X11 and FE65 bind to distinct sites on the YENPTY motif of amyloid precursor protein. Mol Cell Biol 16:6229-6241. Medline

Casella L, Monzani E, Roncone R, Nicolis S, Sala A, De Riso A (2002) Formation of reactive nitrogen species at biologic heme centers: a potential mechanism of nitric oxide-dependent toxicity. Environ Health Perspect 110 [Suppl 5]:709-711.

Cory S, Adams JM (2002) The Bcl2 family: regulators of the cellular life-ordeath switch. Nat Rev Cancer 2:647-656. CrossRef Medline

Degterev A, Lugovskoy A, Cardone M, Mulley B, Wagner G, Mitchison T, Yuan J (2001) Identification of small-molecule inhibitors of interaction 
between the BH3 domain and Bcl-xL. Nat Cell Biol 3:173-182. CrossRef Medline

Devi L, Prabhu BM, Galati DF, Avadhani NG, Anandatheerthavarada HK (2006) Accumulation of amyloid precursor protein in the mitochondrial import channels of human Alzheimer's disease brain is associated with mitochondrial dysfunction. J Neurosci 26:9057-9068. CrossRef Medline

Evan GI, Vousden KH (2001) Proliferation, cell cycle and apoptosis in cancer. Nature 411:342-348. CrossRef Medline

Giliberto L, Zhou D, Weldon R, Tamagno E, De Luca P, Tabaton M, D'Adamio L (2008) Evidence that the Amyloid beta Precursor Proteinintracellular domain lowers the stress threshold of neurons and has a "regulated" transcriptional role. Mol Neurodegener 3:12. CrossRef Medline

Guernsey DL, Jiang H, Campagna DR, Evans SC, Ferguson M, Kellogg MD, Lachance M, Matsuoka M, Nightingale M, Rideout A, Saint-Amant L, Schmidt PJ, Orr A, Bottomley SS, Fleming MD, Ludman M, Dyack S, Fernandez CV, Samuels ME (2009) Mutations in mitochondrial carrier family gene SLC25A38 cause nonsyndromic autosomal recessive congenital sideroblastic anemia. Nat Genet 41:651-653. CrossRef Medline

Hail N Jr, Carter BZ, Konopleva M, Andreeff M (2006) Apoptosis effector mechanisms: a requiem performed in different keys. Apoptosis 11: 889-904. CrossRef Medline

Haitina T, Lindblom J, Renström T, Fredriksson R (2006) Fourteen novel human members of mitochondrial solute carrier family 25 (SLC25) widely expressed in the central nervous system. Genomics 88:779-790. CrossRef Medline

Han P, Dou F, Li F, Zhang X, Zhang YW, Zheng H, Lipton SA, Xu H, Liao FF (2005) Suppression of cyclin-dependent kinase 5 activation by amyloid precursor protein: a novel excitoprotective mechanism involving modulation of tau phosphorylation. J Neurosci 25:11542-11552. CrossRef Medline

Hardy JA, Higgins GA (1992) Alzheimer's disease: the amyloid cascade hypothesis. Science 256:184-185. CrossRef Medline

Hoglinger Gu, Melhem NM, Dickson DW, Sleiman PM, Wang LS, Klei L, Rademakers R, de Silva R, Litvan I, Riley DE, van Swieten JC, Heutink P, Wszolek ZK, Uitti RJ, Vandrovcova J, Hurtig HI, Gross RG, Maetzler W, Goldwurm S, Tolosa E, et al (2011) Identification of common variants influencing risk of the tauopathy progressive supranuclear palsy. Nat Genet 43:699-705. CrossRef Medline

Hu CD, Chinenov Y, Kerppola TK (2002) Visualization of interactions among bZIP and Rel family proteins in living cells using bimolecular fluorescence complementation. Mol Cell 9:789-798. CrossRef Medline

Jazwa A, Cuadrado A (2010) Targeting heme oxygenase-1 for neuroprotection and neuroinflammation in neurodegenerative diseases. Curr Drug Targets 11:1517-1531. Medline

Kermer P, Liman J, Weishaupt JH, Bähr M (2004) Neuronal apoptosis in neurodegenerative diseases: from basic research to clinical application. Neurodegener Dis 1:9-19. CrossRef Medline

Kim-Han JS, Dugan LL (2005) Mitochondrial uncoupling proteins in the central nervous system. Antioxid Redox Signal 7:1173-1181. CrossRef Medline

Knott AB, Perkins G, Schwarzenbacher R, Bossy-Wetzel E (2008) Mitochondrial fragmentation in neurodegeneration. Nat Rev Neurosci 9:505-518. CrossRef Medline

Kumar S, Bandyopadhyay U (2005) Free heme toxicity and its detoxification systems in human. Toxicol Lett 157:175-188. CrossRef Medline

Louneva N, Cohen JW, Han LY, Talbot K, Wilson RS, Bennett DA, Trojanowski JQ, Arnold SE (2008) Caspase-3 is enriched in postsynaptic densities and increased in Alzheimer's disease. Am J Pathol 173:1488-1495. CrossRef Medline

Ma T, Zhao Y, Kwak YD, Yang Z, Thompson R, Luo Z, Xu H, Liao FF (2009) Statin's excitoprotection is mediated by sAPP and the subsequent attenuation of calpain-induced truncation events, likely via rho-ROCK signaling. J Neurosci 29:11226-11236. CrossRef Medline

Martin AG, Fearnhead HO (2002) Apocytochrome c blocks caspase-9 acti- vation and Bax-induced apoptosis. J Biol Chem 277:50834-50841. CrossRef Medline

Martin AG, Nguyen J, Wells JA, Fearnhead HO (2004) Apo cytochrome c inhibits caspases by preventing apoptosome formation. Biochem Biophys Res Commun 319:944-950. CrossRef Medline

Ozaki T, Li Y, Kikuchi H, Tomita T, Iwatsubo T, Nakagawara A (2006) The intracellular domain of the amyloid precursor protein (AICD) enhances the p53-mediated apoptosis. Biochem Biophys Res Commun 351:57-63. CrossRef Medline

Pamplona A, Ferreira A, Balla J, Jeney V, Balla G, Epiphanio S, Chora A, Rodrigues CD, Gregoire IP, Cunha-Rodrigues M, Portugal S, Soares MP, Mota MM (2007) Heme oxygenase- 1 and carbon monoxide suppress the pathogenesis of experimental cerebral malaria. Nat Med 13:703-710. CrossRef Medline

Passer B, Pellegrini L, Russo C, Siegel RM, Lenardo MJ, Schettini G, Bachmann M, Tabaton M, D'Adamio L (2000) Generation of an apoptotic intracellular peptide by gamma-secretase cleavage of Alzheimer's amyloid beta protein precursor. J Alzheimers Dis 2:289-301. Medline

Pfanner N, Geissler A (2001) Versatility of the mitochondrial protein import machinery. Nat Rev Mol Cell Biol 2:339-349. CrossRef Medline

Rath PC, Aggarwal BB (1999) TNF-induced signaling in apoptosis. J Clin Immunol 19:350-364. CrossRef Medline

Ring S, Weyer SW, Kilian SB, Waldron E, Pietrzik CU, Filippov MA, Herms J, Buchholz C, Eckman CB, Korte M, Wolfer DP, Müller UC (2007) The secreted beta-amyloid precursor protein ectodomain APPs alpha is sufficient to rescue the anatomical, behavioral, and electrophysiological abnormalities of APP-deficient mice. J Neurosci 27:7817-7826. CrossRef Medline

Ryan KA, Pimplikar SW (2005) Activation of GSK-3 and phosphorylation of CRMP2 in transgenic mice expressing APP intracellular domain. J Cell Biol 171:327-335. CrossRef Medline

Ryter SW, Tyrrell RM (2000) The heme synthesis and degradation pathways: role in oxidant sensitivity. Heme oxygenase has both pro- and antioxidant properties. Free Radic Biol Med 28:289-309. CrossRef Medline

Sinclair PR, Gorman N, Jacobs JM (2001) Measurement of heme concentration. Curr Protoc Toxicol Chapter 8:Unit 83.

Su JH, Deng G, Cotman CW (1997) Bax protein expression is increased in Alzheimer's brain: correlations with DNA damage, Bcl-2 expression, and brain pathology. J Neuropathol Exp Neurol 56:86-93. CrossRef Medline

Tamayev R, Zhou D, D'Adamio L (2009) The interactome of the amyloid beta precursor protein family members is shaped by phosphorylation of their intracellular domains. Mol Neurodegener 4:28. CrossRef Medline

Walsh DM, Klyubin I, Fadeeva JV, Cullen WK, Anwyl R, Wolfe MS, Rowan MJ, Selkoe DJ (2002) Naturally secreted oligomers of amyloid beta protein potently inhibit hippocampal long-term potentiation in vivo. Nature 416:535-539. CrossRef Medline

Yu SW, Wang H, Poitras MF, Coombs C, Bowers WJ, Federoff HJ, Poirier GG, Dawson TM, Dawson VL (2002) Mediation of poly(ADP-ribose) polymerase-1-dependent cell death by apoptosis-inducing factor. Science 297:259-263. CrossRef Medline

Zhang YW, Xu H (2007) Molecular and cellular mechanisms for Alzheimer's disease: understanding APP metabolism. Curr Mol Med 7: 687-696. CrossRef Medline

Zhang YW, Wang R, Liu Q, Zhang H, Liao FF, Xu H (2007) Presenilin/ gamma-secretase-dependent processing of beta-amyloid precursor protein regulates EGF receptor expression. Proc Natl Acad Sci U S A 104: 10613-10618. CrossRef Medline

Zheng H, Koo EH (2011) Biology and pathophysiology of the amyloid precursor protein. Mol Neurodegener 6:27. CrossRef Medline

Zheng H, Jiang M, Trumbauer ME, Sirinathsinghji DJ, Hopkins R, Smith DW, Heavens RP, Dawson GR, Boyce S, Conner MW, Stevens KA, Slunt HH, Sisoda SS, Chen HY, Van der Ploeg LH (1995) beta-Amyloid precursor protein-deficient mice show reactive gliosis and decreased locomotor activity. Cell 81:525-531. CrossRef Medline 